




\section{NBS SPECIAL PUBLICATION}

\section{$400-13$}

U.S. DEPARTMENT OF COMMERCE / National Bureau of Standards

Nomoinl Burcall of S anoarcs

Library, E.01 Admin. Bidg

OCT 11981

191026

Bemiconductor Meosurement Technilngy:

Improved Infrared Response

Technique for Detecting Defects and Impurities in Germanium and Silicon $p$ - $i-n$ Diodes

\footnotetext{
QC 100

.457 no.400.13

1975

c.2
} 
The National Bureau of Standards' was established by an act of Congress March 3, 1901. The Bureau's overall goal is to strengthen and advance the Nation's science and technology and facilitate their effective application for public benefit. To this end, the Bureau conducts research and provides: (1) a basis for the Nation's physical measurement system, (2) scientific and technological services for industry and government, (3) a technical basis for equity in trade, and (4) technical services to promote public safety. The Bureau consists of the Institute for Basic Standards, the Institute for Materials Research, the Institute for Applied Technology, the Institute for Computer Sciences and Technology, and the Office for Information Programs.

THE INSTITUTE FOR BASIC STANDARIS provides the central basis within the United States of a complete and consistent system of physical measurement; coordinates that system with measurement systems of other nations; and furnishes essential services leading to accurate and uniform physical measurements throughout the Nation's scientific community, industry, and commerce. The Institute consists of a Center for Radiation Research, an Office of Measurement Services and the following divisions:

Applied Mathematics - Electricity - Mechanics - Heat - Optical Physics - Nuclear Sciences ${ }^{2}$ - Applied Radiation ${ }^{2}$ - Quantum Electronics ${ }^{3}$ — Electromagnetics ${ }^{3}$ - Time and Frequency ${ }^{3}$ - Laboratory Astrophysics ${ }^{3}$ - Cryogenics 3 .

THE INSTITUTE FOR MATERIALS RESEARCH conducts materials research leading to improved methods of measurement, standards. and data on the properties of well-characterized materials needed by industry, commerce, educational institutions, and Government; provides advisory and research services to other Government agencies; and develops, produces, and distributes standard reference materials. The Institute consists of the Office of Standard Reference Materials and the following divisions:

Analytical Chemistry - Polymers - Metallurgy - Inorganic Materials - Reactor Radiation - Physical Chemistry.

THE INSTITUTE FOR APPLIED TECHNOLOGY provides technical services to promote the use of available technology and to facilitate technological innovation in industry and Government; cooperates with public and private organizations leading to the development of technological standards (including mandatory safety standards), codes and methods of test; and provides technical advice and services to Government agencies upon request. The Institute consists of a Center for Building Technology and the following divisions and offices:

Engineering and Product Standards — Weights and Measures - Invention and Innovation - Product Evaluation Technology - Electronic Technology - Technical Analysis - Measurement Engineering - Structures, Materials, and Life Safety - Building Environment ${ }^{*}$ - Technical Evaluation and Application ${ }^{4}$ - Fire Technology.

THE INSTITUTE FOR COMPUTER SCIENCES AND TECHNOLOGY conducts research and provides technical services designed to aid Government agencies in improving cost effectiveness in the conduct of their programs through the selection, acquisition, and effective utilization of automatic data processing equipment; and serves as the principal focus within the executive branch for the development of Federal standards for automatic data processing equipment, techniques, and computer languages. The Institute consists of the following divisions:

Computer Services - Systems and Software - Computer Systems Engineering - Information Technology.

THE OFFICE FOR INFORMATION PROGRAMS promotes optimum dissemination and accessibility of scientific information generated within NBS and other agencies of the Federal Government; promotes the development of the National Standard Reference Data System and a system of information analysis centers dealing with the broader aspects of the National Measurement System; provides appropriate services to ensure that the NBS staff has optimum accessibility to the scientific information of the worid. The Office consists of the following organizational units:

Office of Standard Reference Data - Office of Information Activities - Office of Technical Publications - Library - Office of International Relations.

1 Headquarters and Laboratories at Gaithersburg, Maryland, unless otherwise noted; mailing address Washington, D.C. 20234.

${ }^{2}$ Part of the Center for Radiation Research.

3 Located at Boulder, Colorado 80302.

- Part of the Center for Buiding Technology. 


\title{
Improved Infrared Response Technique for Detecting Defects and Impurities in Germanium and Silicon p-i-n Diodes
}

\author{
A. H. Sher
}

Electronic Technology Division

Institute for Applied Technology

National Bureau of Standards

Washington, D.C. 20234

t. Special publucation no. $400-13$

Sponsored by:

U.S. Atomic Energy Commission

Washington, D.C. 20545

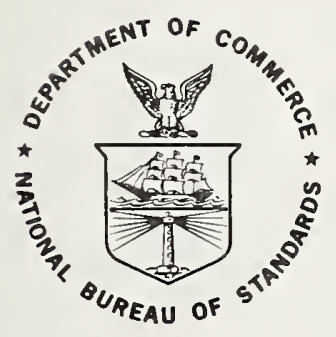

U.S. DEPARTMENT OF COMMERCE, Frederick B. Dent, Secretary NATIONAL BUREAU OF STANDARDS, Richard W. Roberts, Director 


\section{Library of Congress Cataloging in Publication Data}

\section{Sher, Alvin $\mathrm{H}$}

Improved Infrared Response Technique for Detecting Defects and Impurities in Germanium and Silicon $p-i-n$ Diodes.

(Semiconductor Measurement Technology) (National Bureau of Standard Special Publication; 400-13)

Supt. of Docs. No.: C13.10:400-13

1. Germanium Diodes-Defects. 2. Silicon Diodes-Defects. 3. Infra-red technology. I. United States. Atomic Energy Commission. II. Title. III. Series. IV. Series: United States. National Bureau of Standards. Special Publication; 400-13.

QC100.U57 No. 400-13 [TK7871.86] 389'.08s 621.3815'22 75-1210

\section{National Bureau of Standards Special Publication 400-13}

Nat. Bur. Stand. (U.S.), Spec. Publ. 400-13, 26 pages (Feb. 1975)

CODEN: XNBSAV 
Semiconductor Measurement Technology:

Improved Infrared Response Technique for Detecting Defects and Impurities in Germanium and Silicon $p-i-n$ Diodes

A. H. Sher

Table of Contents

Page

Preface . . . . . . . . . . . . . . . iv

1. Introduction. . . . . . . . . . . . . . . 2

2. Initial Measurements. . . . . . . . . . 2

3. Mechanism for Diode Impurity Photovoltage (IRR) . . . . 3

4. IRR Measurements on Germanium . . . . . . . . . 4

4.1 IRR Spectrum Types .............. 5

5. IRR Measurements on Silicon ........... 8

6. Identification of Energy Levels . . . . . . . . 9

6.1 Energy Levels in Germanium ........... . 10

6.2 Energy Levels in Silicon ............ . 11

7. Conclusions . . . . . . . . . . . . . 11

8. References.................. 12 
The Semiconductor Technology Program serves to focus NBS efforts to enhance the performance, interchangeability, and reliability of discrete semiconductor devices and integrated circuits through improvements in measurement technology for use in controlling device fabrication processes and in specifying materials and devices in national and international commerce. Its major thrusts are the development of carefully evaluated and well documented test procedures and associated technology, for use on production lines and in the exchange of devices and materials, and the dissemination of such information to the electronics community. Application of the output by industry is expected to contribute to higher yields, lower cost, and higher reliability of semiconductor devices. In addition, the improvements in measurement technology will lead to greater economy in government procurement and will provide a basis for controlled improvements in fabrication processes and in essential device characteristics.

Cooperation with industrial users and suppliers of semiconductor devices is achieved through NBS participation in standardizing organizations; through direct consultations with device and material suppliers, government agencies, and other users; and through periodically scheduled symposia and workshops. In addition, progress reports are regularly prepared for issuance in the NBS Special Publication 400 sub-series. More detailed reports such as state-of-the-art reviews, literature compilations, and summaries of technical efforts conducted within the Program are issued as these activities are completed. Reports of this type which are publishe by NBS also appear in the Special Publication 400 sub-series. Announcements of availability of all publications in this sub-series are sent by the Government Printing Office to those who have requested this service. A request form for this purpose may be found at the end of this report. 
IMPROVED INFRARED RESPONSE TECHNIQUE FOR DETECTING DEFECTS AND IMPURITIES IN GERMANIUM AND SILICON $p-i-n$ DIODES*

\author{
A. H. Sher \\ Institute for Applied Technology \\ National Bureau of Standards \\ Washington, D.C. 20234
}

\begin{abstract}
An infrared response (IRR) technique was evaluated for its utility in qualifying germanium for radiation detector use. Because of several improvements in the sensitivity and interpretation of the technique made during the evaluation, it was possible to observe a number of discrete energy levels lying within the forbidden energy gap of germanium which had passed unobserved in previous studies. These levels correlate with the type of defects and vacancies introduced by radiation damage into germanium as measured using such techniques as photoconductivity and Hall effect measurements after irradiation. Furthermore, the improved infrared response measurement method was used to identify impurities, such as copper, gold, and iron, and dislocations resulting from
\end{abstract} heat treatments in germanium. A major advance was made when it was determined that the IRR spectra could be grouped into five distinct types on the basis of spectral features observed in the energy range from 0.6 to $0.7 \mathrm{eV}$. One of the spectrum types represented crystals from which good quality detectors could be fabricated; the other four represented crystals that yielded poorer quality detectors due to carrier trapping, or crystals that presented problems such as low lithium drift mobility in detector fabrication. Three of the four spectrum types representative of poor crystal quality could be duplicated by suitably degrading specimens of a good quality crystal. The material and detector characteristics of crystals within each spectrum type were found to be similar.

Key Words: Carrier trapping; gamma-ray detector; germanium; Ge(Li) detector; infrared response; silicon.

\footnotetext{
* Work supported by the AEC Division of Biomedical and Environmental Research
} 
Armantrout introduced a method that made use of the response of $p-i-n$ diodes to monochromatic infrared radiation to identify trapping centers in material intended for use in fabricating Ge(Li) detectors [1]. Further investigation of this infrared response (IRR) technique was undertaken in order to corroborate the previously published findings and determine the applicability of the method. In the process, modifications were made that enhanced the sensitivity and scope of the measurement. This is manifested by increased observation of details in the IRR spectra and led to a better interpretation of energy levels arising from impurities and defects in both germanium and silicon crystals.

\section{INITIAL MEASUREMENTS}

In the IRR measurement, photons incident on a reverse-biased $p-i-n$ diode induce the formation of free carriers in the depleted region of the device by excitation of carriers into or out of energy levels within the band gap. The current due to the generation of free carriers and the subsequent transport of these carriers to the electrodes of the diode is measured as a function of the incident photon energy. The diodes used in this study were, in most cases, lithium-drifted germanium gamma-ray spectrometer structures. These structures are produced by first thermally diffusing lithium, a donor impurity, into single crystal p-type germanium doped with an acceptor impurity, usually gallium. The resulting $p-n$ junction is reverse-biased so that the mobile lithium ions drift into the crystal under the influence of the applied field. The lithium-ion donors compensate the charge of the acceptors present and produce a compensated region that contains few free charge carriers. This compensated or depleted region, sandwiched between the n-type diffused layer and remaining bulk $p$-type crystal, is sensitive to radiation. Figure 1 shows IRR spectra obtained from four lithium-compensated $p-i-n$ germanium diodes using apparatus similar to that used in the original work [1] except that a grating (rather than a prism) monochromator and a phasesensitive amplifier were employed [2]. The results are similar to those previously observed. Diodes NBS 83-3 and NBS 83-4 were fabricated from specimens of the same p-type germanium single crystal; the former was subjected only to the typical lithium-drifted detector fabrication process while the latter was, in addition, heated to $800^{\circ} \mathrm{C}$ and quenched to room temperature. Diodes NBS 13 and NBS $13 \mathrm{Cu}$ were fabricated from specimens of a germanium crystal with an initially high dislocation density $\left(10^{4} \mathrm{~cm}^{-3}\right)$. Diode NBS $13 \mathrm{Cu}$ was also doped with electrically active copper to a density of approximately $1 \times 10^{14} \mathrm{~cm}^{-3}$. All that could be inferred from the IRR spectra of the four diodes on the basis of the previous studies [1] is that all the diodes except diode NBS 83-3 would show some degree of carrier trapping due to their observed response below approximately $0.7 \mathrm{eV}$ and that diode NBS 13 exhibits the lithiumdefect interaction as manifested by the shelflike response at $0.50 \mathrm{eV}$.

Considerably more information was obtained by improving the apparatus used to measure diode IRR by using I-mm thick germanium filter windows 
rather than the 3 to 4-mm thickness previously used. Figure 2 shows the IRR spectrum of diode NBS 83-3 obtained using the improved IRR technique; for the first time in this type of measurement the spectrum exhibits features which can be attributed to discrete levels rather than a continuum of states within the band gap as previously observed [1]. Assuming that the features indicated in figure 2 correspond to actual transitions into or out of energy levels within the band gap, the level scheme that can be constructed is in general agreement with those obtained from measurements of photoconductivity on radiation-damaged germanium [3].

The IRR spectra for the four diodes described above obtained using a 1-mm-thick germanium filter window are shown in figure 3 . In contrast to the spectra in figure 1, those shown in figure 3 permit more positive identification of the origins of the spectral features. For example, the features in the spectrum of diode $\mathrm{NBS} 13 \mathrm{Cu}$ at 0.38 and $0.49 \mathrm{eV}$, corresponding to the known energy levels related to the presence of copper at $0.33 \mathrm{eV}$ above the valence band and $0.22 \mathrm{eV}$ below the conduction band, respectively [4], confirm the presence of that impurity in the test diode. The spectrum exhibited by diode NBS 83-4, the heat-treated specimen, is in agreement with a recent photoconductivity study [5] of the acceptor levels in germanium caused by plastic deformation which showed a broad spectral response corresponding to a continuum of states extending from approximately 0.4 to $0.6 \mathrm{eV}$, with a peaked response at $0.58 \mathrm{eV}$.

The peak at $0.36 \mathrm{eV}$ (one-half the bandgap energy) shown in all the spectra in figure 3 is thought to arise from higher-order diffracted radiation present in the monochromator; peaks also observed at energies of 0.24 and $0.18 \mathrm{eV}$ corresponding to one-third and one-quarter of the bandgap, respectively, seem to bear this out.

\section{MECHANISM FOR DIODE IMPURITY PHOTOVOLTAGE (IRR)}

A review of the literature on measurements of energy levels arising from the presence of defects and impurities in semiconductors by photoconductivity and related techniques has suggested that the steady-state photo-EMF, or photovoltage, established when minority carriers are generated by illumination is probably the basic mechanism for the IRR in $p-i-n$ diodes with wide $i$-regions [6]. Figure 4 illustrates possible models whereby a photovoltage due to light in the impurity region (with energy less than the bandgap energy) can be observed in a diode near liquid nitrogen temperature, $77 \mathrm{~K}$.

As shown in figure $4 \mathrm{a}$, excitation by light in the impurity region can lead to optical transitions from the valence band, $E_{V}$, to an energy state which is empty or only partially occupied by electrons at equilibrium [7]. Double-optical transitions can also occur, as shown in figure 4b, where light transfers electrons from filled states to the conduction band, $\mathrm{E}_{\mathrm{c}}$. The equilibrium between these energy states and the valence band is upset and can be reestablished by subsequent opticallyinduced transitions from $\mathrm{E}_{\mathrm{V}}$ to these states. Double-optical transitions are possible only if the energy of the exciting light is greater than one-half of the forbidden energy gap [7]. Furthermore, excitation with light of energy near the bandgap energy can produce "overpopulation" (charge exchange) of impurity or defect states which may lead to the 
generation of a photovoltage. This is illustrated in figure $4 \mathrm{c}$ which represents the equilibrium energy level scheme of a semiconductor containing three levels in the forbidden gap. Upon illumination with light of energy equal to or greater than the bandgap energy (figure 4d) the electrons and holes produced by such excitation are captured by different states. Nonequilibrium electrons from the conduction band may be captured by level III establishing a steady-state population. Then holes may be captured by both level II and level III [8].

That the above photovoltage effects are responsible for the diode IRR is supported by the following observations made on germanium diodes $[6,9]$ and confirmed in work with silicon. Firstly, no, spectral features that can be linked to impurity or defect states have been seen at incident photon energy less than one-half the bandgap energy. Secondly, the IRR spectrum exhibits evidence of many discrete levels when a thin semiconductor filter is used. Thinner filters transmit more radiation of energy near the bandgap energy than do thicker filters.

Even though the photovoltage is only observed at energies greater than one-half the bandgap energy, it is possible to observe energy states which lie in both halves of the forbidden gap. The photovoltage is observed if the photon energy exceeds the energy difference between the state through which excitation is occurring and the edge of the conduction or valence band, whichever is greater [8].

\section{IRR MEASUREMENTS ON GERMANIUM}

Infrared response measurements were carried out on two high-purity germanium detectors in which lithium-compensation was not used. Figure 5 shows IRR spectra obtained from these two high-purity diodes [10] and also from lithium drifted diode NBS 83-3. Diode NBS 112 was fabricated from a crystal with an initial net donor concentration of approximately $7 \times 10^{10} \mathrm{~cm}^{-3}$. Relative to diode NBS 83-3, diode NBS 112 exhibits a conspicuous lack of structure in the spectrum between 0.50 and $0.54 \mathrm{eV}$, presumably because of the absence of lithium.

Diode NBS 113, the other high purity specimen, was intentionally doped with gold to a density of approximately $10^{11} \mathrm{~cm}^{-3}$. Gold is known to introduce three acceptor levels in germanium located $0.05 \mathrm{eV}$ and $0.15 \mathrm{eV}$ above the valence band and $0.20 \mathrm{eV}$ below the conduction band, and a donor level $0.04 \mathrm{eV}$ below the conduction band [4]. The spectrum of diode NBS 113 shown in figure 5 shows evidence for the presence of levels at $0.57 \mathrm{eV}(0.15 \mathrm{eV}$ above the valence band), $0.66 \mathrm{eV}(0.05 \mathrm{eV}$ above the valence band), and $0.52 \mathrm{eV}$ ( 0.20 below the conduction band).

Diode NBS 301 was fabricated from a crystal pulled from a melt which was contaminated with a chunk of stainless steel [11]. Levels in germanium arising from iron impurity are at energies of $0.34 \mathrm{eV}$ above the valence band and $0.27 \mathrm{eV}$ below the conduction band [4], and chromium introduces levels extending from 0.07 to $0.12 \mathrm{eV}$ above the valence band [4]. The IRR spectrum of diode NBS 301 shown in figure 6 is interpreted to confirm the presence of these impurities by virtue of the incompletely resolved peak at $0.37 \mathrm{eV}$ (iron level at $0.34 \mathrm{eV}$ above the valence band) 
shown in the inset and the "smearing" of the spectrum in the region extending from about 0.64 to $0.59 \mathrm{eV}$ (chromium levels) relative to the spectrum of diode NBS 83-3. Diode NBS 83-6, whose spectrum is also shown in figure 6, was fabricated from a specimen of the same crystal as diode NBS 83-3, but after the lithium diffusion it was stored at room temperature for several months, resulting in lithium precipitation during the storage period. Lithium precipitate clusters would induce strain in the crystal lattice giving rise to a band of energy levels [1]. This is believed to account for the smoothing out of the IRR spectrum of diode NBS 83-6 relative to that of diode NBS 83-3.

While IRR spectra for lithium-drifted diodes with similar measured detector trapping characteristics may not be completely identical, the following comments can be made from a study of the spectra. In diodes which exhibit preferential electron trapping, the level at $0.50 \mathrm{eV}$ is always observed in the IRR spectrum. This level corresponds to the lithium-defect trap located $0.21 \mathrm{eV}$ below the conduction band which has been found to be an electron trap [1]. Figure 7 shows IRR spectra obtained from four lithium-drifted diodes two of which (diodes NBS 88 and NBS 303) exhibit marked electron trapping.

In diodes which exhibit preferential hole trapping (diodes NBS 74 and NBS 76), the level at $0.50 \mathrm{eV}$ is not observed. The IRR spectra of this type of diode show a response that increases smoothly from $0.40 \mathrm{eV}$, peaks at about $0.56 \mathrm{eV}$ and decreases to a valley near $0.59 \mathrm{eV}$.

The IRR spectrum resulting from neutron-irradiation of germanium was also studied for two diodes fabricated from specimens of the same crystal [12]. The portion of the crystal from which diode NBS 83-8 was fabricated had been irradiated with neutrons to a fluence of approximately $1.3 \times 10^{10} \mathrm{~cm}^{-2}$. The IRR spectra of the two diodes, NBS 83-3 and NBS 83-8, are shown in figure 8. It is evident that features in the spectrum of diode NBS $83-8$ at energies of $0.55,0.61$, and $0.63 \mathrm{eV}$ are enhanced over those in the spectrum of diode NBS 83-3. The other features of the spectrum of diode NBS 83-3 appear to be preserved in the spectrum of diode NBS 83-8.

In studying radiation-damaged material, possible annealing effects must be considered. A published study of high-temperature annealing of defects produced by neutron irradiation of germanium [13] at fluences in the range $10^{15}$ to $10^{16} \mathrm{~cm}^{-2}$ is particularly appropriate to the present case as the temperature range studied includes the temperatures employed in the fabrication process for lithium-drifted diodes. After irradiation, four energy states were reported, located at $0.01,0.07$, and $0.17 \mathrm{eV}$ above the valence band and $0.20 \mathrm{eV}$ below the conduction band. After annealing, a new level $0.10 \mathrm{eV}$ below the conduction band was observed. With the exception of the state located $0.01 \mathrm{eV}$ above the valence band which is not within the energy range shown in figure 8 , these states correspond to the features labeled in the figure.

\subsection{IRR SPECTRUM TYPES}

A study of infrared response spectra obtained from lithium-drifted germanium detectors showed that spectra observed to date can be grouped 
into five types: one representative of good quality detectors and four representative of poor quality detectors [14].

Figure 9 shows a comparison of IRR spectra obtained from five Ge(Li) detectors fabricated from crystals from five different suppliers [curves (1) through (5)] with spectra obtained from four specimens of one crystal, each treated in a different manner [curves (A) through (D)]. From previous studies and a review of pertinent literature, it has been concluded that, in general, the energy region covered in figure 9, 0.57 to $0.70 \mathrm{eV}$, is that in which crystalline imperfections are detected; most of the features of these spectra arising from impurities fall below $0.57 \mathrm{eV}$ in the IRR measurements. The spectra of these detectors exhibit distinct features that serve as the basis for dividing IRR spectra into the five types. The characteristics of each type of IRR spectrum are given in table 1 .

\section{Table 1 - Characteristics of Infrared Response Spectrum Types}

\begin{tabular}{|c|c|c|}
\hline Spectrum $^{a}$ & $\begin{array}{l}\text { Energy Position } \\
\text { of Minimum (eV) }\end{array}$ & $\begin{array}{l}\text { Energy Position of } \\
\text { Major Features }(\mathrm{eV})\end{array}$ \\
\hline (1), (A) & 0.66 & 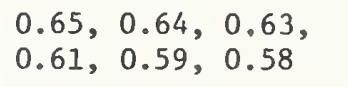 \\
\hline$(2),(B)$ & 0.65 & $0.63,0.61$ \\
\hline (3), (C) & 0.68 & $0.66,0.65,0.64$ \\
\hline (4), (D) & --- & $0.67,0.66,0.65$ \\
\hline (5) & 0.66 & $0.65,0.63,0.61$ \\
\hline
\end{tabular}

Comments

Rises sharply into bandedge above $0.66 \mathrm{eV}$.

Rises sharply into bandedge above $0.65 \mathrm{eV}$.

Rises into bandedge above $0.68 \mathrm{eV}$; spectrum decreases below $0.66 \mathrm{eV}$.

No prominent minimum; this type shows the least number of spectrum features (fairly featureless from 0.58 to $0.65 \mathrm{eV}$ ).

Small minimum; sharply rises into bandedge above $0.66 \mathrm{eV}$.

as shown in figure 9

Table 2 summarizes some of the measured material and detector characteristics of the diodes studied. Of particular interest are the four reference diodes, whose IRR spectra are shown on the left side of figure 9. Each reference diode spectrum is set opposite the spectrum type on the right for which similar features are shown. The reference diodes were all fabricated from specimens of germanium crystal NBS 83, and the treatments to which they had been subjected, previously detailed, are summarized in table 2. Diode 83-4 (Spectrum D in figure 9) was heated to $800^{\circ} \mathrm{C}$, quenched to room temperature, and is thought to contain approximately $10^{14} \mathrm{~cm}^{-3}$ thermal defects [15]. That the IRR spectrum of a germanium specimen of known high quality can be modified by specific treatment of 
a crystal to yield spectra similar to that of lesser quality crystals as shown in figure 9, indicates for the first time that the energy region from about 0.57 to $0.70 \mathrm{eV}$ can be used to yield qualitative information on crystalline imperfections in germanium.

Table 2 - Summary of Crystal and Diode Characteristics of Germanium Specimens

\begin{tabular}{|c|c|c|c|c|c|}
\hline Spectrum $^{a}$ & $\begin{array}{l}\text { Diode } \\
\text { No. }\end{array}$ & $\begin{array}{l}\text { Material } \\
\text { Properties }\end{array}$ & $\begin{array}{c}\text { Detector } \\
\text { Properties }\end{array}$ & $\begin{array}{l}\text { Corresponding } \\
\text { Reference } \\
\text { Diode }\end{array}$ & Spectrum $^{a}$ \\
\hline (1) & NBS 619 & $\begin{array}{l}\text { Oxygen conc.: } \\
<10^{14} \mathrm{~cm}^{-3}\end{array}$ & $\begin{array}{l}\text { Good diode, slight } \\
\text { electron trapping }\end{array}$ & $\begin{array}{l}\text { NBS 83-3: } \\
\text { lithium drift } \\
\text { only, good } \\
\text { detretor }\end{array}$ & (A) \\
\hline (2) & NBS 76 & High Li mobility & $\begin{array}{l}\text { Good diode, severe } \\
\text { hole trapping }\end{array}$ & $\begin{array}{l}\text { NBS } 83-8: \\
\text { neutron- } \\
\text { irradiated }\end{array}$ & (B) \\
\hline (3) & NBS 91 & $\begin{array}{l}\text { Low Li mobility, } \\
\text { oxygen conc. } \\
8 \times 10^{14} \mathrm{~cm}^{-3}\end{array}$ & -- & $\begin{array}{l}\text { NBS } 83-6: \\
\text { lithium } \\
\text { precipitates }\end{array}$ & (C) \\
\hline (4) & NBS 13 & $\begin{array}{l}\text { High Li mobility, } \\
\text { high dislocation } \\
\text { density }\end{array}$ & $\begin{array}{l}\text { Very unstable, } \\
\text { diode could not be } \\
\text { maintained }\end{array}$ & $\begin{array}{l}\text { NBS } 83-4: \\
\text { thermal } \\
\text { defects }\end{array}$ & (D) \\
\hline (5) & NBS 302 & -- & $\begin{array}{l}\text { Poor diode, } \\
\text { electron trapping }\end{array}$ & -- & \\
\hline
\end{tabular}

as shown in figure 9.

Of 48 diodes studied, 25 percent exhibited spectra corresponding to that of a good quality gamma-ray detector, type (1). The remainder exhibited spectra of types thought to correspond to detectors of poorer quality: 38 percent like type (2); 12 percent like type (3); 4 percent like type (4); and 21 percent like type (5). Nearly four-fifths of the poorer quality diodes examined fell into types (2) and (5) [16].

Table 3 summarizes the measured material characteristics common to most of the diodes found in each representative group. These characteristics are generally similar to those of the diodes listed in table 2 . It is interesting to note that the crystals yielding the poor quality detectors can be grouped, on the basis of the IRR spectra, into groups representative of two of the major detector problem areas: trapping of one of the charge carriers or poor lithium drift mobility. The problem of poor diode characteristics (reverse leakage current as a function of bias voltage) does not appear to be separately differentiated by IRR. of course, carrier trapping and poor diode characteristics are 
interrelated; if a sufficient field cannot be applied to the device, charge carriers may be trapped before being collected.

Problems manifested by crystals that exhibit IRR spectrum types (3) or (4) seem to be related to either the lithium-oxygen interaction or high dislocation density, respectively. With regard to carrier trapping, identified with spectrum types (2) and (5), the problem is more complex. The origin of spectrum type (5) has not been identified. Spectrum type (2) is characteristic of the neutron-irradiated reference diode, but it is not possible at present to link the defects known to be produced in germanium by neutron irradiation directly with the defects that produce IRR spectra of this type in the test crystais.

Table 3 - Material Properties of Lithium-Drifted Germanium Detectors

$\begin{array}{cccc}\begin{array}{c}\text { Spectrum } \\ \text { Type }\end{array} & \begin{array}{c}\text { Dislocation } \\ \text { Density }\end{array} & \begin{array}{c}\text { Oxygen } \\ \text { Density }\end{array} & \begin{array}{c}\text { Lithium } \\ \text { Mobility }\end{array} \\ 1 & <2500 \mathrm{~cm}^{-2} & <2 \times 10^{14} \mathrm{~cm}^{-3} & \text { High } \\ 2 & <3500 \mathrm{~cm}^{-2} & <3 \times 10^{14} \mathrm{~cm}^{-3} & \text { High } \\ 3 & >5000 \mathrm{~cm}^{-2} & >5 \times 10^{14} \mathrm{~cm}^{-3} & \text { Low } \\ 4 & >10^{4} \mathrm{~cm}^{-2} & >1 \times 10^{13} \mathrm{~cm}^{-3} & \text { High } \\ 5 & 2500-8000 \mathrm{~cm}^{-2} & <2 \times 10^{14} \mathrm{~cm}^{-3} & \text { High }\end{array}$

\section{IRR MEASUREMENTS ON SILICON}

Concurrent with the IRR study of germanium, IRR work on silicon nuclear radiation detectors was carried out $[6,12]$. The results of these measurements, mainly from radiation-damage experiments, were used to support the interpretation of IRR results on germanium.

Figure 10 shows IRR spectra obtained for a lithium-drifted silicon detector before and after irradiation with fast neutrons through the $p$-contact to a fluence of $5 \times 10^{9} \mathrm{~cm}^{-2}$ [12]. As might be expected for such a fluence the two spectra are nearly the same. However, the peaks at 0.86 and $0.77 \mathrm{eV}$ are somewhat enhanced, and the feature at $0.93 \mathrm{eV}$ is much enhanced after irradiation. The two lower energy peaks are associated with levels located $0.40 \mathrm{eV}$ below the conduction band $(0.77 \mathrm{eV})$ and $0.31 \mathrm{eV}$ above the valence band $(0.86 \mathrm{eV})$. Such levels have been previously reported from observations of photoconductivity on silicon specimens irradiated with neutrons at fluences from $1 \times 10^{16}$ to $5 \times 10^{19} \mathrm{~cm}^{-2}$ and are attributed to divacancies [17].

Figure 11 shows IRR spectra obtained from three commercial lithiumdrifted silicon detectors presumed to be fabricated from specimens of the same silicon crysta1. Diode NBS-3S was not irradiated, diode NBS-4S was irradiated with $1.9-\mathrm{MeV}$ protons to a fluence of $1 \times 10^{14} \mathrm{~cm}^{-2}$ incident on the p-contact, and diode NBS-5S was irradiated with $1.5-\mathrm{MeV}$ electrons to a fluence of approximately $3 \times 10^{13} \mathrm{~cm}^{-2}$ incident on the p-contact. 
The spectra of diodes NBS-3S and NBS-4S are similar as might be expected since damage caused by $1.9-\mathrm{MeV}$ protons should be localized in the contact region and not in the compensated region of the device. As in the case of NBS-6S (figure 10), the main features are observed at 0.77 and $0.86 \mathrm{eV}$, and $1.03 \mathrm{eV}$. The IRR spectrum of the electron-irradiated specimen, diode NBS-5S, shows features at 0.99 , and $0.90 \mathrm{eV}$ as well as those at $0.93,0.86$, and $0.77 \mathrm{eV}$ observed in the other silicon diodes, and attributed to divancies after electron irradiation [18]. In the literature, a level located $0.18 \mathrm{eV}$ below the conduction band $(0.99 \mathrm{eV})$ arising from the vacancy-oxygen complex has been reported after neutronand gamma-irradiation $[19,20]$, while a level $0.27 \mathrm{eV}$ above the valence $(0.90 \mathrm{eV})$ may be associated with lithium precipitates [21].

Since the commercial lithium-drifted silicon detectors used in this study had gold p-contacts, approximately 15 to $20 \mathrm{~nm}$ thick, through which the infrared radiation must pass, it was necessary to determine what effects, if any, this thin contact had on the measurement of IRR. The infrared transmission of a $0.14-\mathrm{mm}$ thick silicon filter, the thickness used in the measurement of the IRR of silicon detectors, was measured using a thermocouple detector both before and after evaporation of approximately $15 \mathrm{~nm}$ of gold onto one side of the filter. No effect was observed in the spectral distribution of the radiation; however, the overall transmission was reduced by a factor of about three as compared to the uncoated filter.

\section{IDENTIFICATION OF ENERGY LEVELS}

In connection with a comprehensive study of methods for the evaluation of germanium suitable for use in $\mathrm{Ge}(\mathrm{Li})$ detectors, 85 germanium specimens were collected between 1967 and 1973. Most of these had been rejected for use in the fabrication of high-quality $\mathrm{Ge}(\mathrm{Li})$ detectors. Infrared response spectra from 55 of these specimens were identified as to spectrum type; the remaining specimens were of insufficient thickness to permit the fabrication of diodes, were damaged during processing, or yielded IRR spectra whose type could not be identified due to excess noise.

In early IRR measurements, good agreement had been found between energy levels determined from the energies of IRR spectral features and energy levels arising from radiation damage experiments in germanium [3]. However, at that time no attempt was made to distinguish whether features seen in IRR measurements were associated with levels in the upper or in the lower half of the forbidden energy gap. If the various levels observed in IRR spectra could be uniquely identified based on data in the technical literature, and thus linked to a specific crystalline defect, then it might be possible for the crystal grower to identify the source of the defect in the crystal growth procedure. If corrective action could be taken, the quality of the crystal could be upgraded based on the IRR data. 
After a review of the literature concerning energy levels resulting from radiation or thermal damage in germanium as measured either by photoconductivity or Hal1 effect [13,23-46], an attempt was made to link features in the IRR spectra specifically with energy levels observed in the literature [22]. The results are shown in figure 12. From the data published on fast neutron, proton, gamma ray, fast electron, and thermal damage, etc., the summary of energy levels shown in column B was obtained. The shaded bars indicate the energy range of levels for which there were some discrepancy in reported energy but which appeared to arise from the same center. In column A are shown energy levels resulting from IRR measurements of diode NBS 83-3. In this case each energy level appears only once in the scheme; the level was placed at the appropriate energy either below the conduction band edge or above the valence band edge using the levels shown in column $B$ as the basis for comparison. In the majority of cases, a feature observed in the IRR spectrum can be linked uniquely on the basis of energy with a level or band of levels obtained from the summary of the results reported in the literature.

The energy level located $0.18 \mathrm{eV}$ above the valence band (observed at an energy of about $0.54 \mathrm{eV}$ in IRR spectra) is reported to arise specifically from the divacancy-lithium (VVLi) complex and thus should not be observed in lithium-free germanium $[38,46]$. Comparison of the IRR spectra obtained from a lithium-drifted diode, NBS 83-3, and from a diode fabricated from high-purity germanium (without lithium compensation), NBS-112, confirms this expectation. The spectrum of NBS 83-3 exhibits a feature at $0.54 \mathrm{eV}$, but the spectrum of NBS-112 does not.

It is possible to make some specific statements, on the basis of IRR measurements, with regard to the nature of trapping centers in Ge(Li) detectors. Table 4 summarizes the data on the two IRR spectrum types covering detectors that exhibit hole or electron trapping.

Table 4 - Energy Levels in Ge(Li) Detectors Exhibiting Trapping

\begin{tabular}{|c|c|c|c|c|}
\hline $\begin{array}{l}\text { Spectrum } \\
\text { Type }\end{array}$ & $\begin{array}{l}\text { Carrier } \\
\text { Trapped }\end{array}$ & $\begin{array}{l}\text { Level } \\
(\mathrm{eV})\end{array}$ & $\begin{array}{l}\text { Nature of } \\
\text { Energy Level }{ }^{b}\end{array}$ & Reference \\
\hline (2) & hole & $\begin{array}{l}E_{c}-0.09 \\
E_{v}+0.11\end{array}$ & $\begin{array}{l}\text { Vo complex } \\
\text { VVLio complex }\end{array}$ & [33] \\
\hline (5) & electron & $\begin{array}{l}E_{v}+0.07 \\
E_{c}-0.09 \\
E_{v}+0.11 \\
E_{c}-0.21\end{array}$ & $\begin{array}{l}\text { VVLi complex } \\
\text { Vo complex } \\
\text { VVLio complex } \\
\text { VVLio complex }\end{array}$ & $\begin{array}{c}{[41,51]} \\
{[33]} \\
{[44]} \\
{[44]}\end{array}$ \\
\hline
\end{tabular}

\footnotetext{
as shown in figure 9

${ }^{\text {b }}$ V - vacancy, WV - divancy, Li - Iithium, 0 - oxygen
} 
Work on growing high purity germanium indicates that residual oxygen creates charge trapping centers in this material [54]. Thus the assignment of $\mathrm{LiO}^{+}$as the donor species in those levels thought to arise from WD complexes $\left(E_{\mathrm{V}}+0.11 \mathrm{eV}\right.$ and $\left.E_{\mathrm{C}}-0.21 \mathrm{eV}[46]\right)$ seems reasonable. That the main electron trap in $\mathrm{Ge}(\mathrm{Li})$ detectors must lie deeper than $0.175 \mathrm{eV}$ [55], appears to point to the $E_{C}-0.21 \mathrm{eV}$ level which is not observed in hole-trapping crystals.

\subsection{ENERGY LEVELS IN SILICON}

The energy level scheme in figure 13 is a summary of the state of the IRR measurements on radiation-damaged, lithium-drifted silicon nuclear radiation detectors. As in the case of germanium, energy levels reported in the literature $[17,18,20,47,50-53]$ are listed in column $B$, while energy levels observed in IRR measurements are listed in column A. Tentative identification of IRR-detected levels with corresponding levels reported in the literature has been made previously [6].

\section{CONCLUSIONS}

It has been demonstrated that the IRR technique can be used to qualitatively detect and identify impurities and defects in germanium and silicon with a high degree of sensitivity. In the case of lithium-drifted nuclear radiation detectors, the technique can be used as a predictor of crystal suitability for detector use early in the fabrication process. Similarly, the results of such measurements regarding the presence of certain types of defects in germanium and silicon single crystals should be useful to the crystal grower to better control the growing process.

Given suitable sources of optical radiation, the IRR technique should be applicable to a wide range of semiconductor materials from which diodes can be fabricated. In the case of discrete microelectronic devices (transistors and diodes) the technique might be extended to studies of impurities and defects. This would be useful in analyzing device failure and, in particular, radiation damage effects. 
1. Armantrout, G. A., Infrared Evaluation Techniques for Ge(Li) Detectors, IEEE Trans. Nucl. Sei. NS-17, No. 1, 16-23 (1970).

2. Sher, A. H., and Keery, W. J., Improved Infrared-Response Technique for Determining Impurity and Defect Levels in Semiconductors, Appl. Phys. Lett. 20, No. 3, 120-122 (1972).

3. Methods of Measurement for Semiconductor Materials, Process Contro1, and Devices, W. M. Bullis, ed., NBS Tech. Note 571, pp. 16-18 (April 1971).

4. Neuberger, M., Electronic Properties Information Center, Report DS-143 (1965); available from NTIS, Springfield, VA., Accession Number AD 610828.

5. Miles, M. H., Extrinsic Photoconductivity from Edge Dislocations in Germanium, J. App Z. Phys. 40, 2720-2724 (1969).

6. Sher, A. H., Liu, Y. M., and Keery, W. J., Infrared Response Measurements on Radiation-Damaged Si(Li) Detectors, IEEE Trans. Nucl. Sci. NS-19, No. 3, 312-317 (1972).

7. Ryvkin, S.M., Photoelectric Effects in Semiconductors, pp. 369-373 (Consultants Bureau, New York, 1964).

8. Berkovskii, F. M., and Ryvkin, S. M., Sensitivity of Germanium and Silicon Photoce11s in the Impurity Excitation Region, Sov. Phys.-Solid State 4, 263-269 (1962).

9. Sher, A. H., Keery, W. J., and Dyson, H. E., Improved Infrared Response Measurements in Semiconductor Nuclear Radiation Detectors, IEEE Trans. Ancl. Sci. NS-19, 341-344 (1972).

10. Diodes supplied by R. D. Baertsch, General Electric Company, Schenectady, NY., 12301.

11. Crystal Supplied by I. L. Fowler, AECL, Chalk River Nuclear Laboratories, Chalk River, Ontario, Canada.

12. Methods of Measurement for Semiconductor Materials, Process Control, and Devices, W. M. Bullis, ed., NBS Tech. Note 727, pp. 16-21 (June 1972).

13. Konopleva, R. F., Novikov, S. R., and Ryvkin, S. M., High-Temperature Annealing of Defects Produced by Fast Neutrons in Germanium, Sov. Phys.-Solid State $\underline{6}$, 2610-2612 (1965).

14. Methods of Measurement for Semiconductor Materia1s, Process Contro1, and Devices, W. M. Bullis, ed., NBS Tech. Note 733, pp. 17-23 (September 1972).

15. Logan, R. A., Thermally Induced Acceptors in Germanium, Phys. Rev. 101, 1455-1459 (September 1972).

16. Methods of Measurement for Semiconductor Materials, Process Contro1, and Devices, W. M. Bullis, ed., NBS Tech. Note. 743, pp. 17-22 (December 1972).

17. Lappo. M. T., and Tkachev, V. D., Divacancies in Silicon Irradiated with Fast Neutrons, Sov. Phys.-Semiconductors 4, 1882-1884 (1971).

18. Young, R. C., and Corel1i, J. C., Infrared Photoconductivity of Electron-Irradiated Phosphorous-Doped Silicon, Air Force Cambridge Research Laboratories Final Report (August 1, 1971). Available from National Technical Information Service, Springfield, Virginia 22151, Accession Number AD 729477.

19. Daly D. F., and Noffke, H. E. An EPR Study of Fast Neutron Radiation Damage in Silicon, Rad. Effects 8. 203-211 (1971). 
20. Konozenko, I. D., Semenyak, A. K., and Khivrich, V. I., Radiation Defects Created by $\mathrm{Co}^{60} \gamma$-Rays in $p$ - and n-Type Silicon of High Purity, Phys. Stat. Sol. 35, 1043-1052 (1969).

21. Smirnova, I. V., Chapnin, V. A., and Vavilov, V. S., Radiation Defects in LithiumDoped Silicon, Sov. Phys.-Solid State 4, 2469-2474 (1962-63).

22. Methods of Measurement for Semiconductor Materials, Process Control, and Devices, W. M. Bullis, ed., NBS Tech. Note 773, pp. 14-20 (June 1973).

23. Konopleva, R. F., Novikov, S. R., and Ryvkin, S. M., Energy Levels in Germanium Induced by Fast-Neutron Bombardment, Sov. Phys.-Solid State 5, 1345-1351 (1964).

24. Novikov, S. R., Rubinova, E. E., and Ryvkin, S. M., Photoconductivity of Germanium Irradiated with Fast Neutrons, Sov. Phys.-Solid State 6, 690-691 (1964).

25. Novikov, S. R., and Rubinova, E. E., Fhotoconductivity of Germanium Irradiated by Fast Neutrons at $77^{\circ} \mathrm{K}$, Sov. Phys.-Solid State 6, 1037-1049 (1964).

26. Konopleva, R. F., et al., Radiation Defects in Germanium Irradiated with High-Energy Protons, Sov. Phys.-Semiconductors 3, 948-951 (1970).

27. Evseev, V. A., Konopleva, R. F., and Yuferev, A. A., Recombination Properties of $p$ - and n-Type Germanium Irradiated with 660-MeV Protons, Sov. Phys.-Semiconductors 4, 1323-1327 (1971).

28. Evseev, V. A., Konopleva, R. F., and Yuferev, A. A., Investigation of Trapping Phenomena in $p$ - and n-Type Germanium Irradiated with 660-MeV Protons, Sov. Phys.Semiconductors 5, 625-628 (1971).

29. Vitovskii, N. A., Maksimov, M., and Mashovets, T. V., Investigation of $\gamma$-Radiation Defects in High Purity Germanium, Sov. Phys.-Semiconductors 4, 880-886 (1970).

30. Vitovskii, N. A., Mashovets, T. V., and Ryvkin, S..M., High Temperature Annealing of $\gamma$-Radiation Defects in n-Type Germanium, Sov. Phys.-Solid State 6, 148101487 (1964).

31. Gerasimov, A. B., et al., Impurity Photoconductivity in Germanium Due to Ganma-Ray Irradiation, Sov. Phys.-Solid State 6, 2527-2528 (1965).

32. Mashovets, T. V., and Khanserarov, R. Yu., The Energy Structure of $\gamma$-Radiation Defects in Germanium, Sov. Phys.-Solid State 7, 245-246 (1965).

33. Akimchenkov, I. P., Vavilov, V. S., and Plotnikov, A. F., Photoconductivity Spectra of Germanium Doped with Oxygen and Irradiated with Fast Electrons, Sov. Phys.-Solid State 8, 1577-1579 (1967).

34. Gerasimov, A. B., Ryvkin, S. M., and Yaroshetskii, I. D., Impurity Photoconductivity in Germanium Irradiated by Fast Electrons, Sov. Phys.-Solid State 6, 543-550 (1964).

35. Akimchenkov; I. P., Ginzburg, M. I., and Plotnikov, A. F., Spectra and Kinetics of the Photoconductivity of $p$ - and n-Type Germanium Crystals Irradiated with Fast Electrons at 100 and $5.2^{\circ} \mathrm{K}$, Sov. Phys.-Solid State 8, 932-937 (1966).

36. Tkachev, V. D., and Urenev, V. L., Thermal Defects in Crystals of Pure Germanium, Sov. Phys.-Semiconductors 4, 1880-1881 (1971).

37. Abdurakhamonava, S. N., et al., Investigation of Thermal Defects in High-Purity Germanium, Sov. Phys.-Semiconductors 4, 1979-1985 (1971).

38. Sinishchuk, I. K., Tkachev, V. K., and Urenev, V. I., Interaction of Lithium with Radiation Defects in Pure n-Type Germanium, Sov. Phys.-Semiconductors 5, 1910-1911 (1972). 
39. Goncharov, L. A., et aZ., Divacancy Donor Complexes in Oxygen-Free $\gamma$-Irradiated Germanium, Sov. Phys.-Semiconductors 6, 369-370 (1972).

40. Emtzev, V. V., et al., On the Donor-Vacancy Type Complexes in Germanium, Rad. Effects 9, 181-187 (1971).

41. Sinishchuk, P. K, and Abiev, A. K., Changes in the Energy-Leve1 Structure of LithiumDoped Germanium Due to Irradiation with $10^{19} \gamma$-Raýs $/ \mathrm{cm}^{2}$ and Annealing, Sov. Phys.Semiconductor I, 148-149 (1973).

42. Smirnov, G. A., Tkachev, V. D., and Urenev, V. I., Mechanism of the Precipitation of Lithium in Germanium, Sov. Phys.-Semiconductors 7, 1556-1557 (1974).

43. Tkachev, V. D., Urenev, V. I., and Yavid, V. Yu., Recombination Centers in n-Type Germanium, Sov. Phys.-Semiconductors 6, 1549-1550 (1973).

44. Konopleva, R. F., and Novikov, S. R., Formation of Defects in Lithium-Doped Germanium Due to Bombardment with Fast Neutrons, Sov. Phys.-Semiconductors 7 , 906-908 (1974).

45. Basman, A. R., et al., Influence of Donor Impurities in the Kinetics of Annealing of Radiation Defects in Germanium, Sov. Phys.-Semiconductors 7, 922-924 (1974).

46. Sinishchuk, I. K., and Reznikov, M. Ya., Interaction of Lithium with Disordered Regions Formed by Fast.Neutrons in n-Type Germanium, Sov. Phys.-Semiconductors 7, 1131-1132 (1974).

47. Vavilov, V. S., Effects of Radiation on Semiconductors, p. 178 (Consultants Bureau, New York, 1965); contains an energy level scheme compiled from 13 references published up to 1963).

48. Johnson, E. S., and Compton, W. D., Recombination Luminescence in Irradiated Silicon Effects of Thermal Annealing and Lithium Impurity, Rad. Effects 9, 89-92 (1971).

49. Smirnova, I. V., Chapnin, V. A., and Vavilov, V. S., Radiation Defects in LithiumDoped Silicon, Sov. Phys.-Solid State 4, 2469-2474 (1963).

50. Vorobeichik, V. A., Konopleva, R. F., Novikov, S. R., and Rubinova, E. E., Photoelectric Properties of Si Irradiated with 660-MeV Protons, Soc. Phys.-Semiconductors 5, 397-401 (1971).

51. Urli, N. B., Annealing of $\gamma$-Ray Irradiated Lithium Compensated p-Type Silicon, Rad. Effects 9, 93-97 (1971).

52. Kozlov, I. P., et al., Divancy-Oxygen Complexes in Silicon, Sov. Phys.-Semiconductors $\underline{6}, 1743-1744$ (1973).

53. Baranova, E. K., Gusev, V. M., and Stre1'tsov, L. N., Infrared-Absorption Study of Radiation Defects in Silicon Bombarded with Lithium Ions, Sov. Phys.-Semiconductors 6, 2009-2010 (1973).

54. PehI, R. H., Cordi, R. C., and Goulding, F. S., High-Purity Germanium: Detector Fabrication and Performance, IEEE Trans. Nucl. Sci. NS-19, No. 1, 265-269 (1972).

55. McMath, T. A. and Sakai, E., A Search for Deep Trap Levels in Ge(L1) Detectors, IEEE Trans. Nucl. Sci. NS-19, No. 1, 289-294 (1972). 


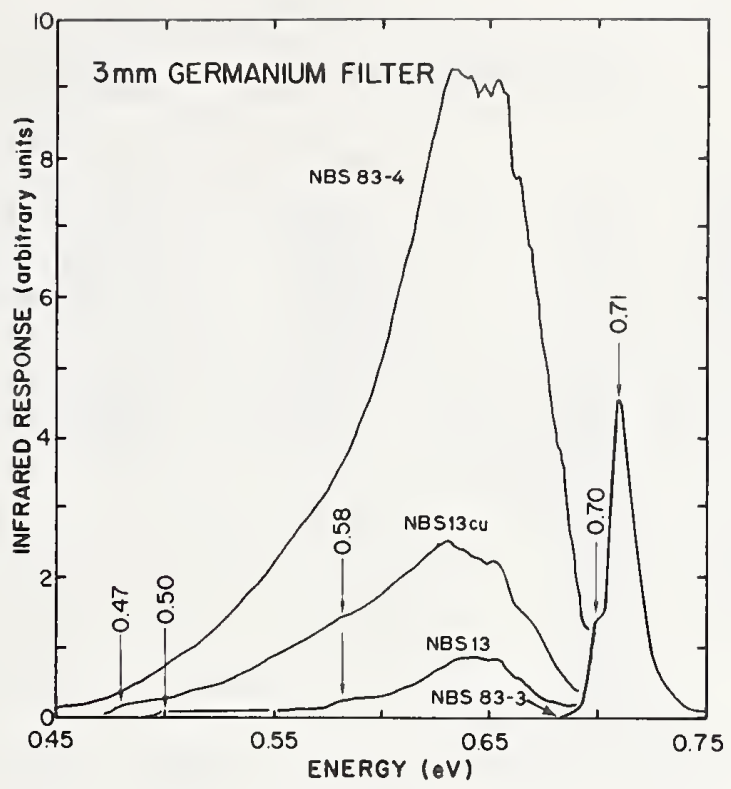

Figure 1. Infrared response obtained using a 3-mm-thick germanium filter. The spectra have been plotted so that the bandedge response peaks of each specimen (at approximately $0.71 \mathrm{eV}$ ) overlap. In order to observe a measurable infrared response below the bandedge peak from NBS 83-3, the signal sensitivity level would had to have been increased by a factor of approximately 200. Specimen temperature was approximately $100 \mathrm{~K}$ [2].

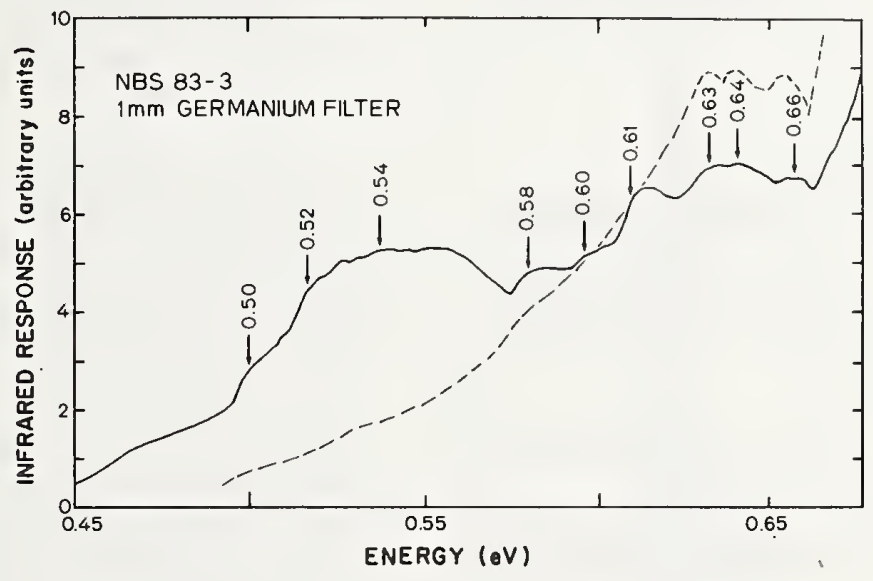

Figure 2. Infrared-response spectrum of NBS 83-3 obtained using a 1-mmthick germanium filter. The dashed curve is that obtained using the 3-mm-thick germanium filter at an enhanced signal sensitivity. Specimen temperature is approximately $100 \mathrm{~K}[2]$. 


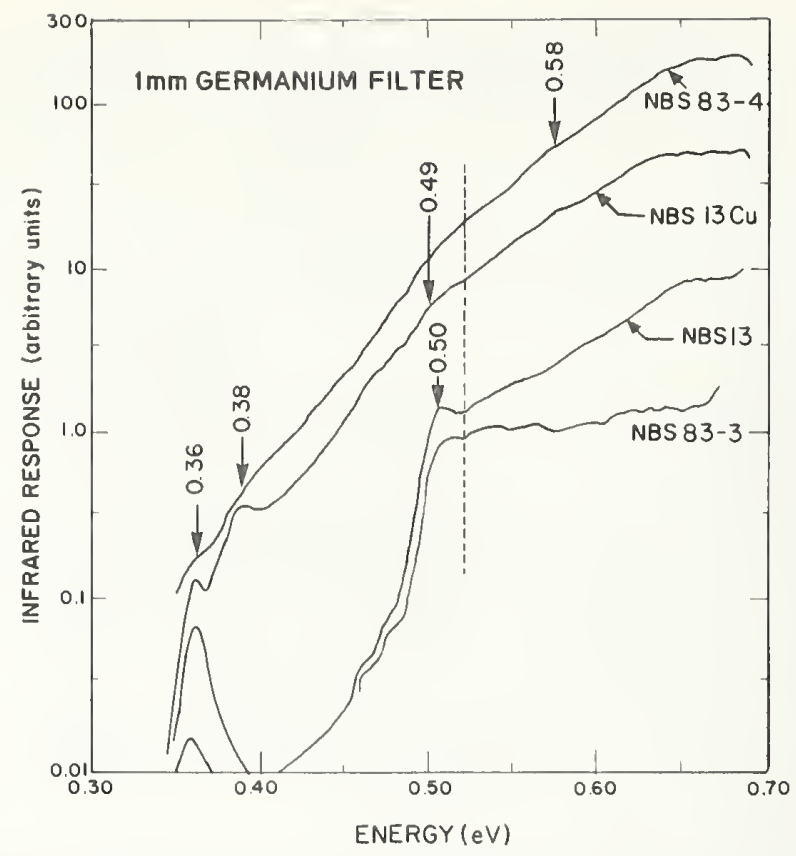

Figure 3. Intrared-response spectra obtained using a 1-mm-thick filter window in the incident photon energy range 0.30 to $0.70 \mathrm{eV}$. (The spectra are plotted so that the levels of the minimum detectable signal coincide. To the right of the dashed line a 640-line/mm grating was employed; to the left 240 1ine/mm.) Specimen temperature was about $100 \mathrm{~K}$ [2].
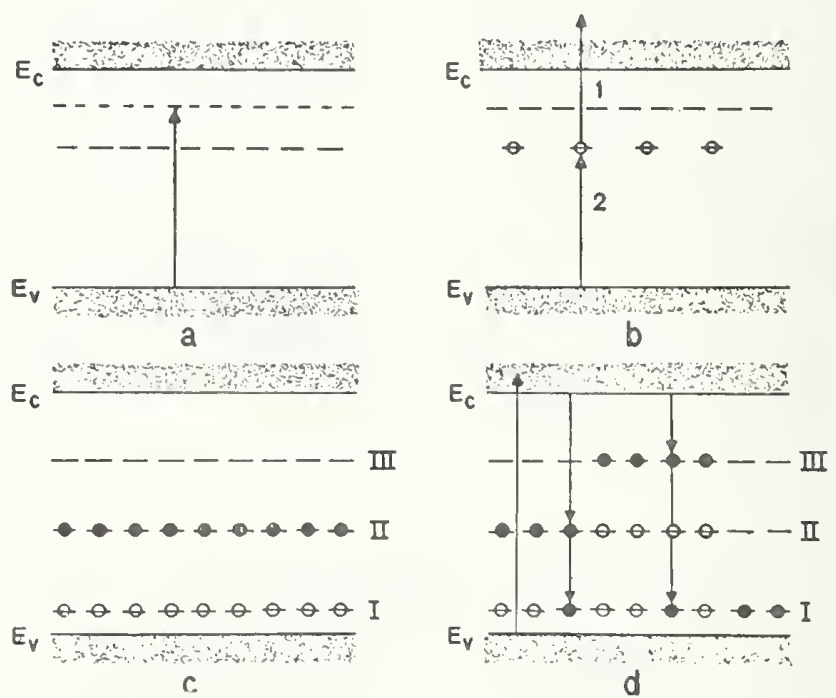

Figure 4. Representations of mechanisms that might yield a photovoltage in $p-i-n$ diode: a) transition from valence band to unfilled level;

b) double-optical transition; c) the equilibrium conditions for the charge exchange process, and d) the transitions for the charge exchange process [6]. 


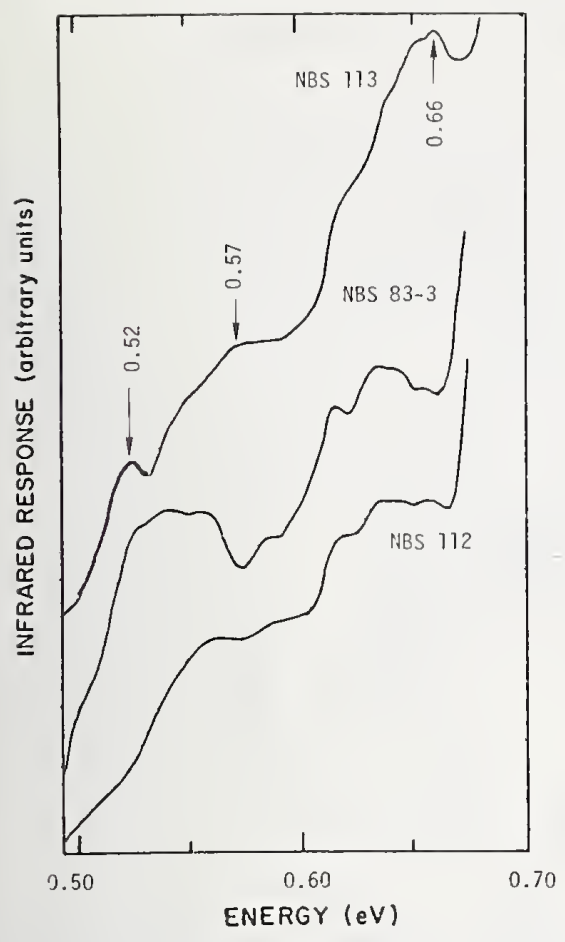

ire 5. IRR spectra of two high purity gerum diodes and NBS 83-3, shown for comparison, ined using a 1-mm thick germanium filter [9].

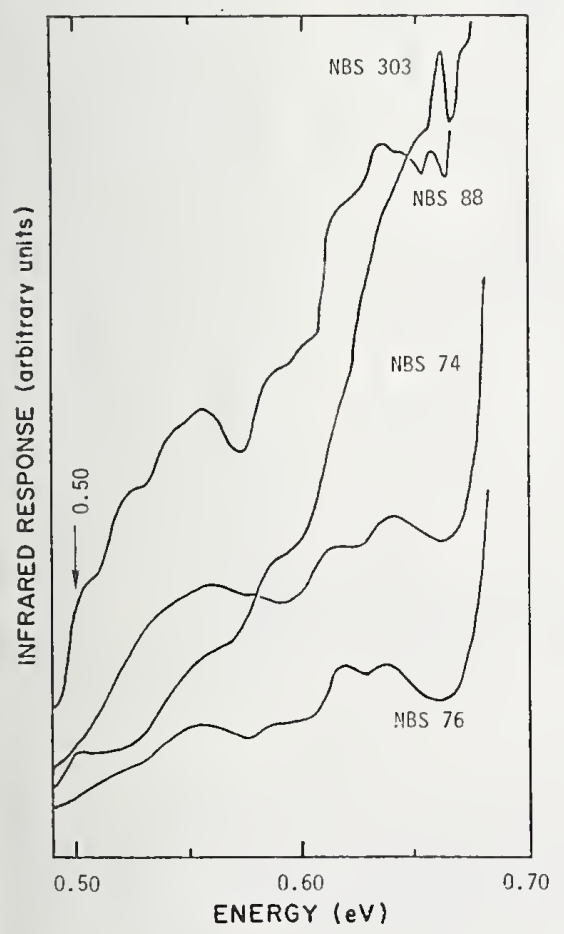

re 7. IRR spectra obtained using a 1-mm thick anium filter from two lithium-drifted gerium diodes that exhibit electron trapping (NBS nd NBS 303) and two diodes that exhibit hole ping (NBS 74 and NBS 76) [9].

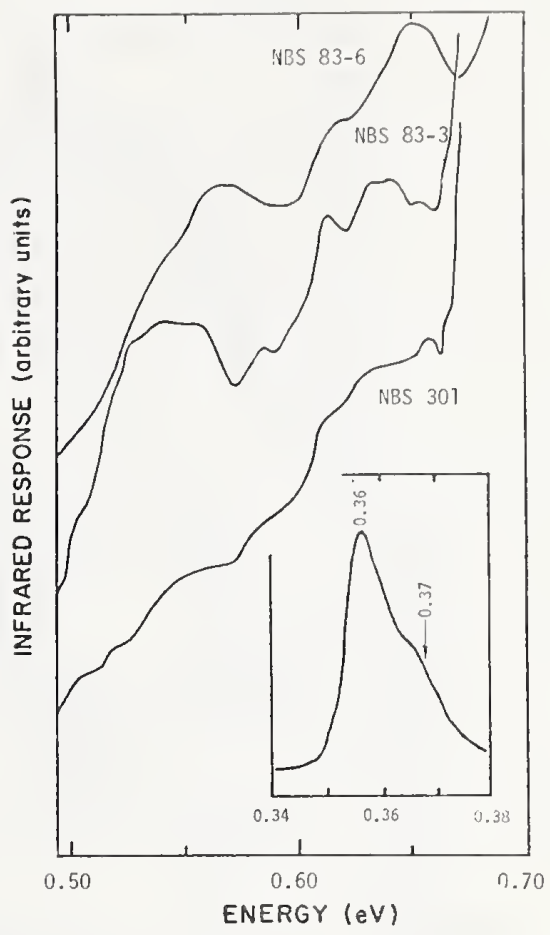

Figure 6. IRR spectra of three 1ithium-drifted germanium diodes obtained using a 1-mm thick germanium filter. Inset shows a portion of the spectrum of NBS 301 [9].

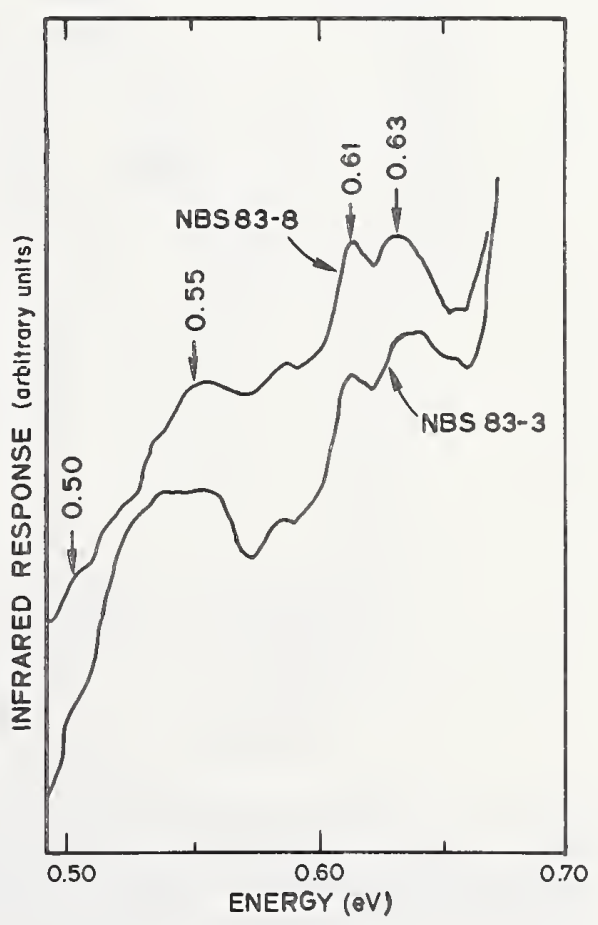

Figure 8. Infrared response spectra of two germanium gamma-ray detectors [12]. 


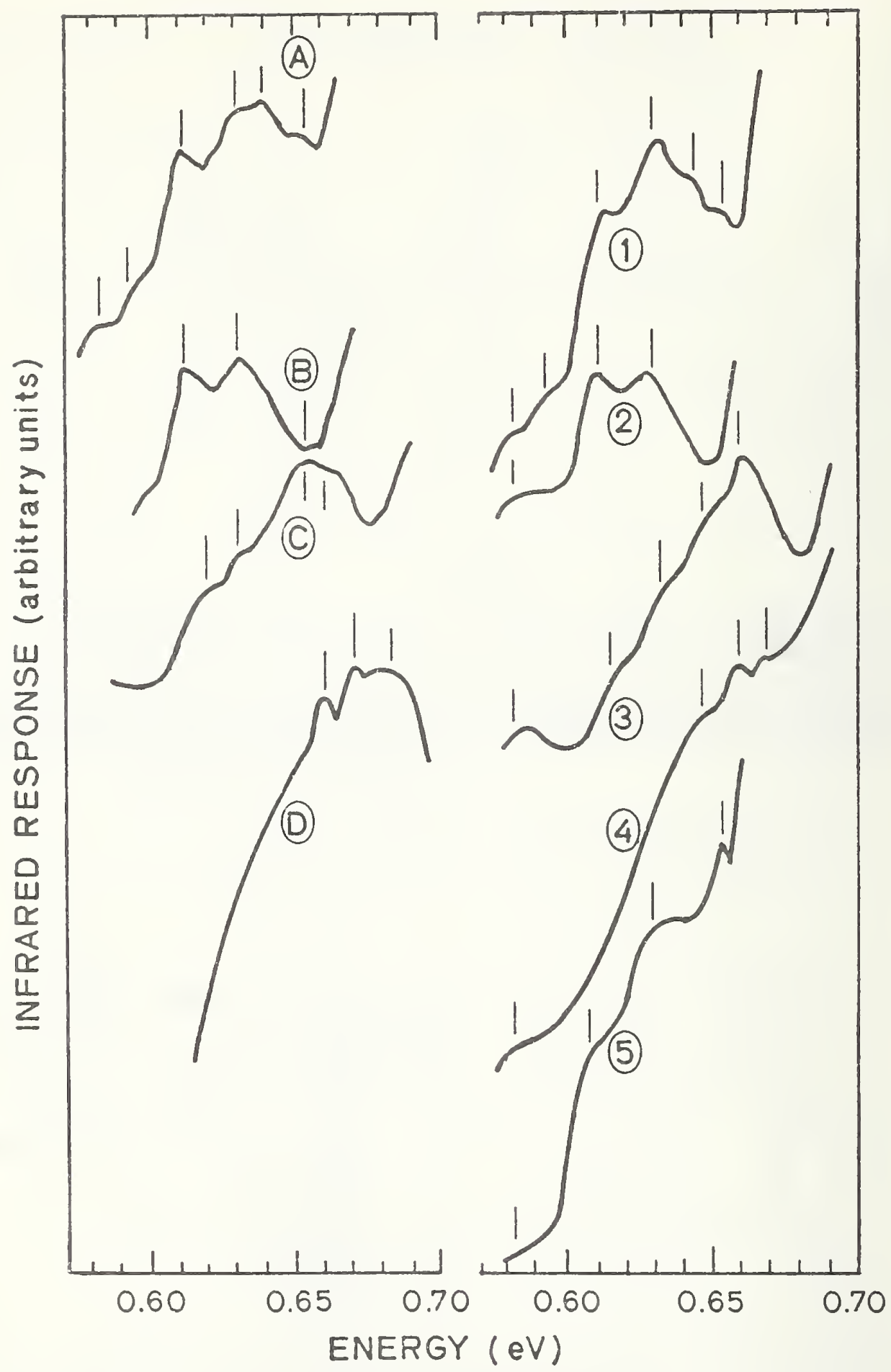

Figure 9. Infrared response spectra obtained from five lithium-drifted germanium diodes fabricated from crystals from five different sources [(1) - (5)] and four diodes fabricated from specimens of another crystal treated in known manners [(A) - (D)]. (Spectral features of interest as indicated by short vertical lines are identified in table 1. The diodes are identified in table 2.) [14]. 


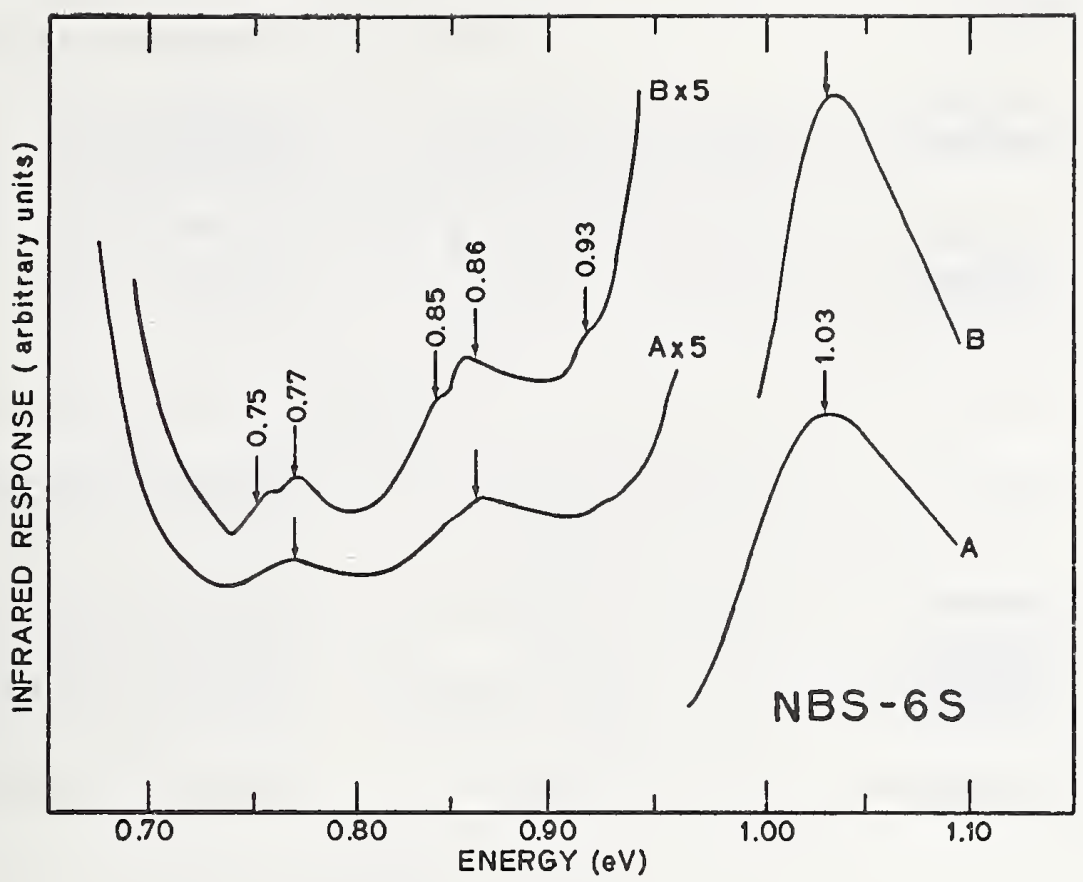

Figure 10. Infrared response spectra of a commercial lithium-drifted silicon detector obtained before (A) and after (B) irradiation with fast neutrons [9].

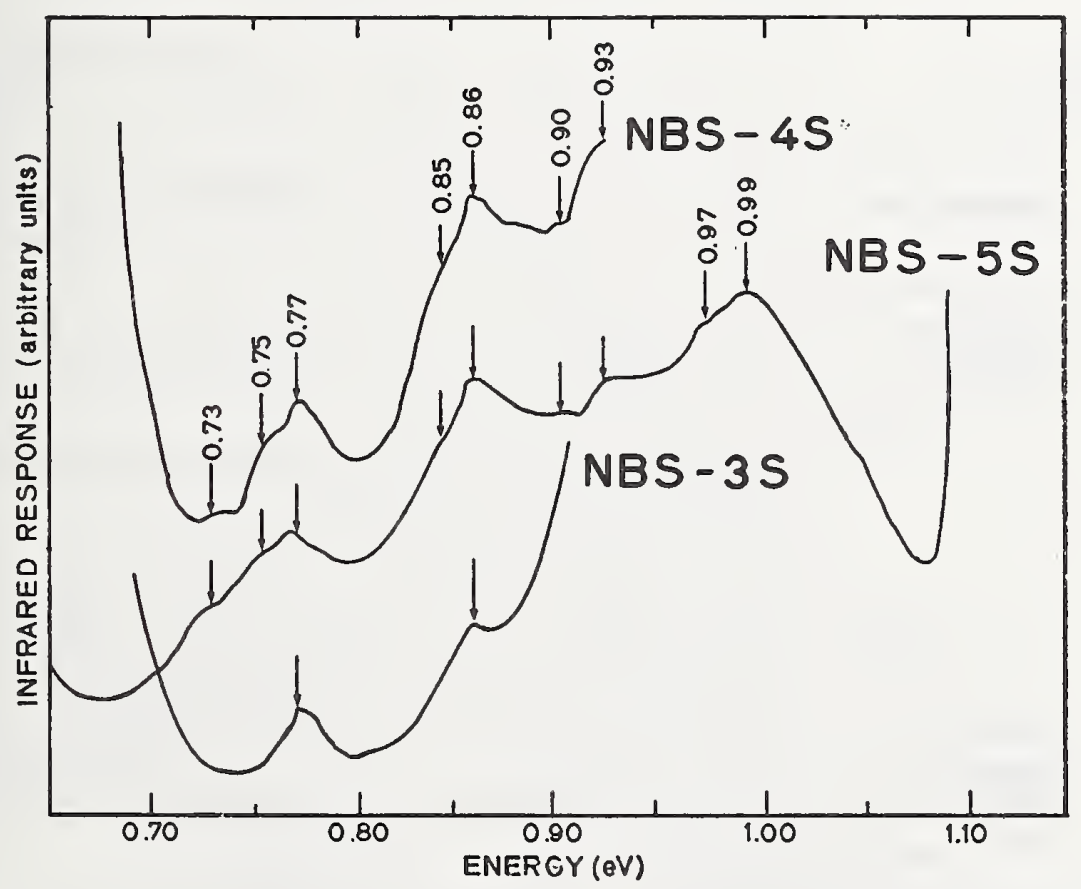

Figure 11. Infrared response spectra of three commercial lithium-drifted silicon detectors. (Large peaks, similar to that in the spectrum of NBS-6S shown in figure 10, occur at $1.03 \mathrm{eV}$ in the spectra of NBS-3S and NBS-4S. These are not shown because they exceed the scale of the figure.) [9]. 


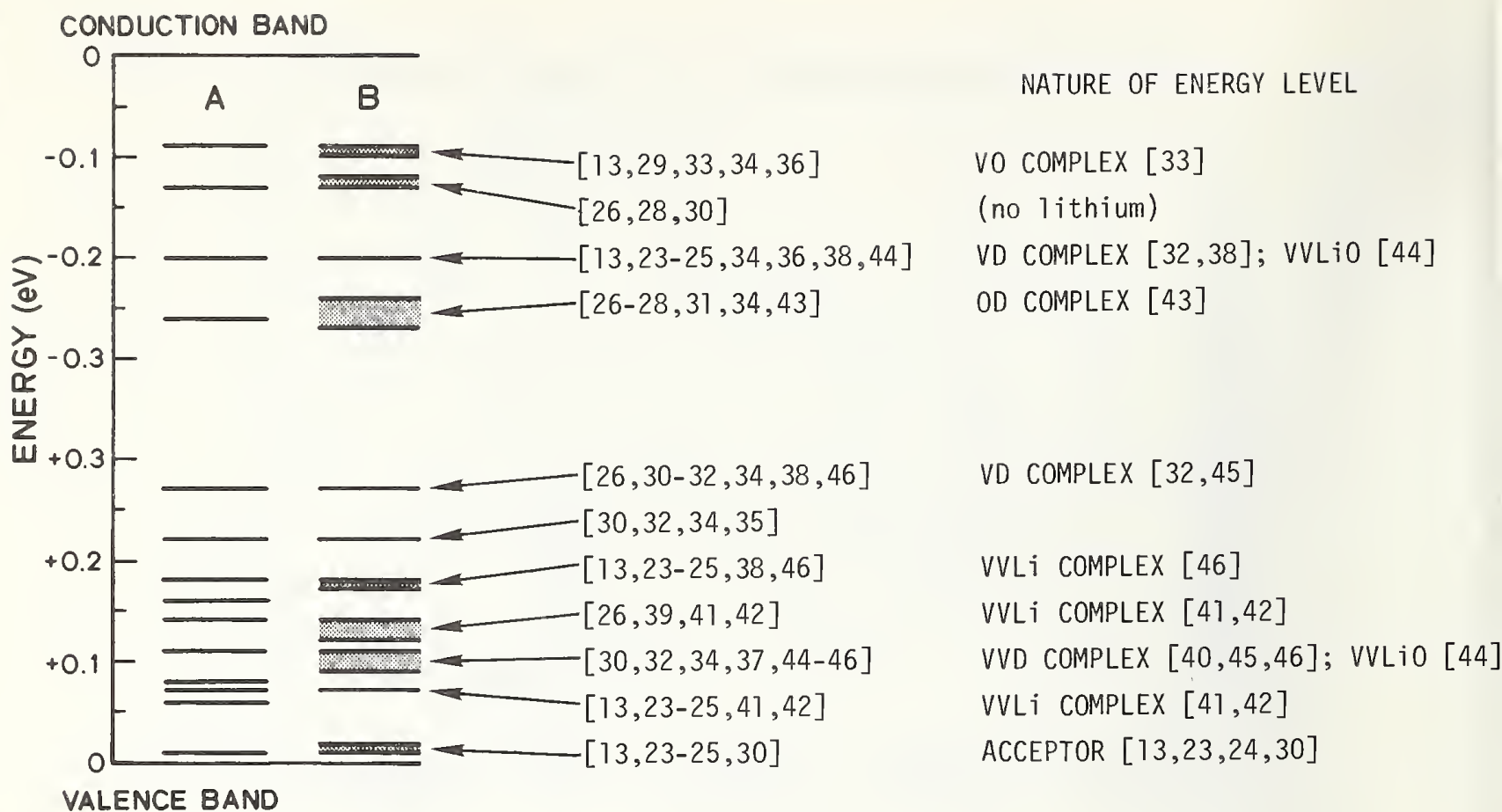

Figure 12. Energy level scheme comparing features detected in IRR measurements on germanium diod (A) with levels resulting from radiation or thermal damage (B). References are given in brackets Symbols used: V-vacancy, VV-divacancy, O-oxygen, D-donor, Li-1ithium [26].

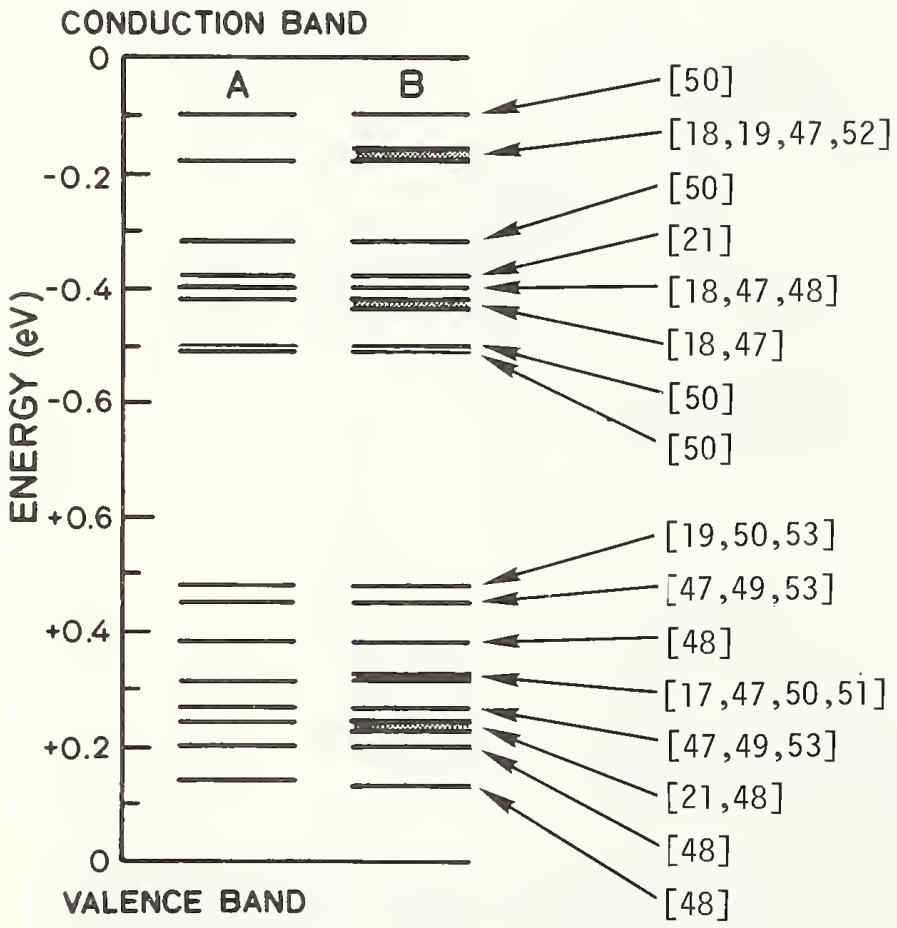

NATURE OF ENERGY LEVEL

VO COMPLEX (A-CENTER) $[18,47,52]$

VD COMPLEX AT LATTICE SITE $[47,48]$

VO COMPLEX (A-CENTER) [50]

VV [19]; VVLi [53]

LITHIUM PRECIPITATE [49], at VV [53] K-CENTER [48]

LiV or LiO COMPLEX $[47,51]$

LITHIUM PRECIPITATE [9], at VV [53] VV [21]

VV [48]

VV [48]

Figure 13. Energy level scheme comparing features detected in IRR measurements on silicon diodes (A) with levels resulting from radiation damage (B). References are given in brackets. Symbols used: V-vacancy, V-divacancy, O-oxygen, D-donor, Li-1ithium [26]. 
U.S. DEPT. OF COMM.

BIBLIOGRAPHIC DATA SHEET

TITLE AND SUBTITLE

Improved Infrared and Impurities ir
1. PUBLICATION OR REPORT NO.

NBS-SP-400-13

Semiconductor Measurement Technology:

Response Technique for Detecting Defects

Germanium and Silicon $p-i-n$ Diodes
2. Gov't Access
No.
nhnology:
ng Defects
odes

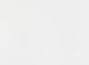

5. Publication Date

AUTHOR(S)

A. H. Sher

PERFORMING ORGANIZATION NAME AND ADDRESS

\author{
NATIONAL BUREAU OF STANDARDS \\ DEPARTMENT OF COMMERCE \\ WASHINGTON, D.C. 20234
}

6. Performing Organization Code

8. Performing Organ, Report No.

10. Project/Task/Work Unit No.

11. Contract/Grant No.

Sponsoring Organization Name and Complete Address (Street, City, State, ZIP)

U. S. Atomic Energy Commission

Division of Biomedical and Environmental Research

Washington, D.C. 20545

13. Type of Report \& Period Covered

Final

\title{
SUPPLEMENTARY NOTES
}

Library of Congress Catalog Number: $75-1210$

ABSTRACT (A 200-word or less factual summary of most significant information. If document includes a significant bibliography or literature survey, mention it here.)

An infrared response (IRR) technique was evaluated for its utility in qualifying germanium for radiation detector use. Because of several improvements in the sensitivity and interpretation of the technique made during the evaluation, it was possible to observe a number of discrete energy levels lying within the forbidden energy gap of germanium which had passed unobserved in previous studies. These levels correlate with the type of defects and vacancies introduced by radiation damage into germanium as measured using such techniques as photoconductivity and Hall effect measurements after irradiation. Furthermore, the improved infrared response measurement method was used to identify impurities, such as copper, gold, and iron, and dislocations resulting from heat treatments in germanium. A major advance was made when it was determined that the IRR spectra could be grouped into five distinct types on the basis of spectral features observed in the energy range from 0.6 to $0.7 \mathrm{eV}$. One of the spectrum types represented crystals from which good quality detectors could be fabricated; the other four represented crystals that yielded poorer quality detectors due to carrier trapping, or crystals that presented problems such as low lithium drift mobility in detector fabrication. Three of the four spectrum types representative of poor crystal quality could be duplicated by suitably degrading specimens of a good quality crystal. The material and detector characteristics of crystals within each spectrum type were found to be similar.

KEY WORDS (six to twelve entries; alphabetical order; capitalize only the first letter of the first key word unless a proper name; separated by semicolons)

Carrier trapping; gamma-ray detector; germanium; Ge(Li) detector; infrared response silicon.

AVAILABILITY

$\mathrm{x}$ Unlimited

For Official Distribution. Do Not Release to NTIS

Order From Sup. of Doc., U.S. Government Printing Office

Washington, D.C. 20402, SD Cat. No. C13 10:400-13

Order From National Technical Information Service (NTIS) Springfield, Virginia 22151

\begin{tabular}{|l|c|}
\hline $\begin{array}{l}\text { 19. SECURITY CLASS } \\
\text { (THIS REPURT) }\end{array}$ & 21. NO. OF PAGES \\
UNCL ASSIFIED & 26 \\
\hline $\begin{array}{l}\text { 20. SECURITY CLASS } \\
\text { (THIS PAGE) } \\
\text { UNCLASSIFIED }\end{array}$ & 22. Price \\
\hline
\end{tabular}


Superintendent of Documents, Government Printing Office, Washington, D.C. 20402

Dear Sir:

Please add my name to the announcement list of new publications to be issued in the series: National Bureau of Standards Special Publication 400-。

Name

Company

Address

City State Zip Code

(Notification Key $\mathrm{N}-413$ ) 


\section{PERIODICALS}

JOURNAL OF RESEARCH reports National Bureau of Standards research and development in physics, mathematics, and chemistry. It is published in two sections, a vailable separately:

- Physics and Chemistry (Section A)

Papers of interest primarily to scientists working in these fields. This section covers a broad range of physical and chemical research, with major emphasis on standards of physical measurement, fundamental constants, and properties of matter. Issued six times a year. Annual subscription: Domestic, $\$ 17.00$; Foreign, $\$ 21.25$.

\section{- Mathematical Sciences (Section B)}

Studies and compilations designed mainly for the mathematician and theoretical physicist. Topics in mathematical statistics, theory of experiment design, numerical analysis, theoretical physics and chemistry, logical design and programming of computers and computer systems. Short numerical tables. Issued quarterly. Annual subscription: Domestic, $\$ 9.00$; Foreign, $\$ 11.25$.

DIMENSIONS/NBS (formerly Technical News Bulletin)-This monthly magazine is published to inform scientists, engineers, businessmen, industry, teachers, students, and consumers of the latest advances in science and technology, with primary emphasis on the work at NBS. The magazine highlights and reviews such issues as energy research, fire protection, building technology, metric conversion, pollution abatement, health and safety, and consumer product performance. In addition, it reports the results of Bureau programs in measurement standards and techniques, properties of matter and materials, engineering standards and services, instrumentation, and automatic data processing.

Annual subscription: Domestic, $\$ 9.45$; Foreign, $\$ 11.85$.

\section{NONPERIODICALS}

Monographs-Major contributions to the technical literature on various subjects related to the Bureau's scientific and technical activities.

Handbooks-Recommended codes of engineering and industrial practice (including safety codes) developed in cooperation with interested industries, professional organizations, and regulatory bodies.

Special Publications-Include proceedings of conferences sponsored by NBS, NBS annual reports, and other special publications appropriate to this grouping such as wall charts, pocket cards, and bibliographies.

Applied Mathematics Series-Mathematical tables, manuals, and studies of special interest to physicists, engineers, chemists, biologists, mathematicians, computer programmers, and others engaged in scientific and technical work.

National Standard Reference Data Series-Provides quantitative data on the physical and chemical properties of materials, compiled from the world's literature and critically evaluated. Developed under a world-wide program coordinated by NBS. Program under authority of National Standard Data Act (Public Iaw 90-396).

NOTE: At present the principal publication outlet for these data is the Journal of Physical and Chemical Reference Data (JPCRD) published quarterly for NBS by the American Chemical Society (ACS) and the American Institute of Physics (AIP). Subscriptions, reprints, and supplements available from ACS, 1155 Sixteenth St. N. W., Wash. D. C. 20056.

Building Science Series-Disseminates technical information developed at the Bureau on building materials, components, systems, and whole structures. The series presents research results, test methods, and performance criteria related to the structural and environmental functions and the durability and safety characteristics of building elements and systems.

Technical Notes-Studies or reports which are complete in themselves but restrictive in their treatment of a subject. Analogous to monographs but not so comprehensive in scope or definitive in treatment of the subject area. Often serve as a vehicle for final reports of work performed at NBS under the sponsorship of other government agencies.

Voluntary Product Standards-Developed under procedures published by the Department of Commerce in Part 10, Title 15, of the Code of Federal Regulations. The purpose of the standards is to establish nationally recognized requirements for products, and to provide all concerned interests with a basis for common understanding of the characteristics of the products. NBS administers this program as a supplement to the activities of the private sector standardizing organizations.

Federal Information Processing Standards Publications (FIPS PUBS)-Publications in this series collectively constitute the Federal Information Processing Standards Register. Register serves as the official source of information in the Federal Government regarding standards issued by NBS pursuant to the Federal Property and Administrative Services Act of 1949 as amended, Public Law 89-306 (79 Stat. 1127), and as implemented by Executive Order 11717 (38 FR 12315, dated May 11, 1973) and Part 6 of Title 15 CFR (Code of Federal Regulations).

Consumer Information Series-Practical information, based on NBS research and experience, covering areas of interest to the consumer. Easily understandable language and illustrations provide useful background knowledge for shopping in today's technological marketplace.

NBS Interagency Reports (NBSIR) - A special series of interim or final reports on work performed by NBS for outside sponsors (both government and non-government). In general, initial distribution is handled by the sponsor; public distribution is by the National Technical Information Service (Springfield, Va. 22161) in paper copy or microfiche form.

Order NBS publications (except NBSIR's and Bibliographic Subscription Services) from: Superintendent of Documents, Government Printing Office, Washington, D.C. 20402 .

\section{BIBLIOGRAPHIC SUBSCRIPTION SERVICES}

The following current-awareness and literature-survey bibliographies are issued periodically by the Bureau: Cryogenic Data Center Current Awareness Service

A literature survey issued weekly. Annual subscrip. tion: Domestic, $\$ 20.00$; foreign, $\$ 25.00$.

Liquefied Natural Gas. A literature survey issued quarterly. Annual subscription: $\$ 20.00$.

Superconducting Devices and Materials. A literature survey issued quarterly. Annual subscription: $\$ 20.00$. Send subscription orders and remittances for the preceding bibliographic services to National Technical Information Service, Springfield, Va. 22161.

Electromagnetic Metrology Current Awareness Service Issued monthly. Annual subscription: $\$ 100.00$ (Special rates for multi-subscriptions). Send subscription order and remittance to Electromagnetics Division, National Bureau of Standards, Boulder, Colo. 80302 . 
